\title{
RIGHT BUNDLE BRANCH BLOCK AND CARDIAC INFARCTION
}

\author{
BY \\ PETER MEYER \\ Received November 16, 1948
}

It is the object of this paper to investigate the modifications of the electrocardiographic pattern of cardiac infarction caused by the simultaneous presence of right bundle branch block, and to describe the cardiographic signs 'on which the diagnosis of infarction can be made in the presence of right branch block. The cardiogram of right branch block shows added changes characteristic of infarction; it differs in this respect from that of left branch block which often masks the evidence of infarction.

An analysis of tracings taken from patients with right bundle branch block but without infarction will be necessary for the study of cardiograms showing the combined lesion and will, therefore, precede it. All cases under review have the cardiographic pattern of the common variety of right branch block; cases of classical right branch block, characterized by a predominantly downward directed main deflection in lead I, a conspicuous $R$ in lead II, and a tall $R$ in lead III, with $T$ waves in the opposite direction of the main deflection, were not included because of their rarity. A series of twenty-three patients were observed personally; the majority were seen in private practice, and their tracings were taken with a Siemens electrocardiograph; seven patients were seen at the Out-Patient Department of the National Heart Hospital, under Dr.
William Evans. A search was made for reported cases to bring the total number of records up to 72 .

\section{Right Bundle Branch Block in Healthy SUBJECTS}

Right bundle branch block is not rare in healthy subjects and was found 7 times when 1445 healthy persons were examined by Wood, Jeffers, and Wolferth (1935). The present analysis is based on 20 cases (see Fig. 1 and Table, Cases 1-20). In 7 cases $Q$ deflections were shown in lead I; they were less frequent and never large in lead II. The upstroke of the main deflection and the beginning of the downstroke were slender and steep as in normal curves. The R-T segment showed no significant depression or elevation except for a gradual rise if the following $\mathrm{T}$ was high and set close to the QRS complex. The $T$ waves were upright in leads $I$ and II in all cases. The chest lead cardiogram of right branch block, made familiar through the work of Wilson and his collaborators (1934, 1944), was examined in 14 cases, and it included leads from the right præcordial area in 11. Lead CR1 or V1 showed a bifid QRS complex, with two peaks above the isoelectric line; in some records the initial peak was of low voltage (see Fig. 1D); there were no $\mathrm{Q}$ waves; the $\mathrm{R}-\mathrm{T}$ segment was either level with the

\section{TABLE OF CASES}

No.

1. Own case

2. Own case

3. Own case

4. Own case

5. Own case

6. Own case

7. Own case

8. Own case

9. Wilson et al...

et al. (1934), Fig.

10. Wilson et al. (1934), Fig. 2

11. Wilson et al. (1934), Fig. 3

12. von Deesten et al. (1934), Fig. 1 .

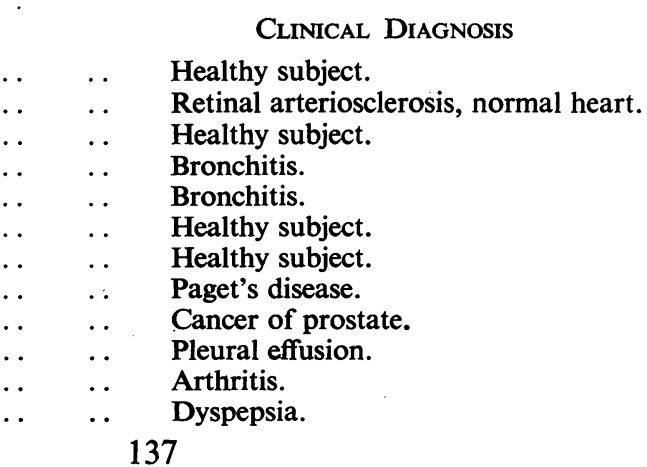


TABLE OF CASES-continued

No. REFERENCE

13. von Deesten et al. (1934), Fig. 2 ..

14. von Deesten et al. (1934), Fig. 3 ..

15. von Deesten et al. (1934), Fig. 4 ..

16. von Deesten et al. (1934), Fig. 5 .

17. Wood et al. (1935), Fig. 1 .

18. Wilson et al. (1944), Fig. 11

19. Wolferth et al. (1947), Fig. 1

20. Goldberger (1947), Fig. 62. .

21. Own case

22. Own case

23. Own case

24. Own case

25. Own case

26. Own case

27. Stenström (1927), Fig. 24 .

28. Wood et al. (1935), Fig. 2 .

29. Evans et al. (1937), Fig. 4 . .

30. Evans et al. (1937), Fig. 5 ..

31. Evans et al. (1937), Fig. 7 . .

32. Evans et al. (1937), Fig. 8 ..

33. Evans et al. (1937), Fig. 9B

34. Evans et al. (1937), Fig. 10

35. Evans et al. (1937), Fig. 12

36. Evans et al. (1937), Fig. 15A

37. Yater (1938), Fig. 1..

38. Conneau et al. (1938), Fig. 1

39. Katz (1941), Fig. 389

40. Wolferth et al. (1947), Fig. 2

41. Wolferth et al. (1947), Fig. 3

42. Own case

43. Own case

44. Own case

45. Own case

46. Own case

47. Levine (1929), Fig. 58

48. Appelbaum et al. (1934), Fig. 28

49. Master et al. (1938), Fig. 2

50. Master et al. (1938), Fig. 7A

51. Master et al. (1938), Fig. 8

52. Katz (1941), Fig. 386C

53. Wilson et al. (1944), Fig. 29

54. Wilson et al. (1944), Fig. 37

55. Wilson et al. (1944), Fig. 38

56. Goldberger (1947), Fig 79A

57. Carlotti (1947), Fig. 8A

58. Curtis Bain et al. (1947), Fig. 17A

59. Curtis Bain et al. (1947), Fig. 17B

60. Soulié et al. (1948), Fig. 7 .

61. Own case

62. Own case

63. Own case

64. Own case

65. Levine (1929), Fig. 9

66. Levine (1929), Fig. 58

67. Evans et al. (1937), Fig. 11

68. Master et al. (1938), Fig.

69. Master et al. (1944), Fig. 1B

70. Wilson et al. (1944), Fig. 39

71. Wolferth et al. (1947), Fig. 4

72. Carlotti (1947), Fig. 8B

\section{Clinical Diagnosis}

Extrasystoles.

Healthy subject.

Healthy subject.

Healthy subject.

Healthy subject.

Ulcerative colitis.

Healthy subject.

Healthy subject.

Hypertension.

Aortic stenosis.

Hypertension, cerebral hæmorrhage, uræmia.

Stokes-Adams syndrome and partial block.

Aortic stenosis.

Hypertensive heart failure.

Heart failure.

Ventricular septal defect.

Congenital heart disease.

Mitral stenosis, fibrillation, hypertension.

Fibrillation.

Hypertensive heart failure.

Heart failure.

Hypertension.

Aortic stenosis.

Heart failure.

Mitral disease.

Rheumatic fever.

Hypertension.

Angina of effort.

Stokes-Adams syndrome.

Recent cardiac infarction.

Cardiac infarction 2 years ago.

Cardiac infarction 2 months ago.

Cardiac infarction 8 years ago.

Cardiac infarction 5 years ago.

Recent cardiac infarction.

Cardiac infarction.

Recent cardiac infarction.

Recent cardiac infarction.

Recent cardiac infarction.

Recent cardiac infarction.

Recent cardiac infarction.

Recent cardiac infarction.

Recent cardiac infarction.

Recent cardiac infarction.

Recent cardiac infarction.

Recent cardiac infarction.

Recent cardiac infarction.

Recent cardiac infarction.

Cardiac infarction 9 months ago.

Cardiac infarction some months ago.

Cardiac infarction some months ago.

Cardiac infarction 3 weeks ago.

Recent cardiac infarction.

Recent cardiac infarction.

Old cardiac infarction.

Old cardiac infarction.

Recent cardiac infarction.

Recent cardiac infarction.

Old cardiac infarction.

Recent cardiac infarction. 


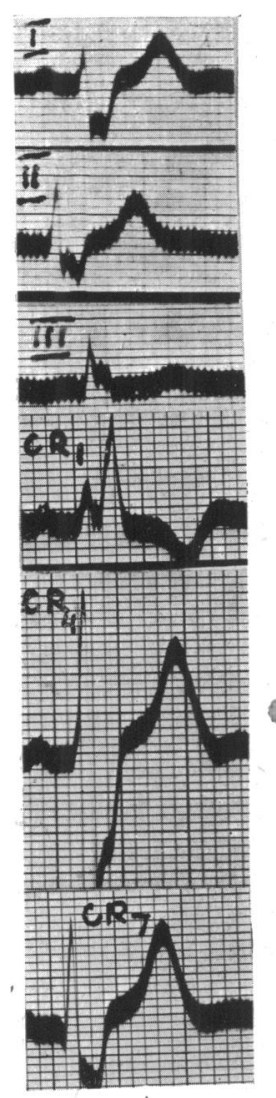

A

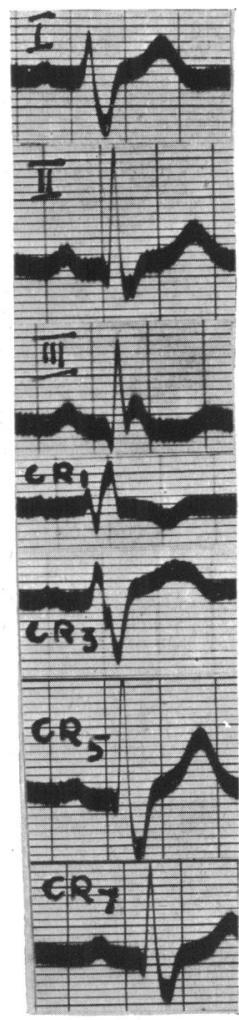

B
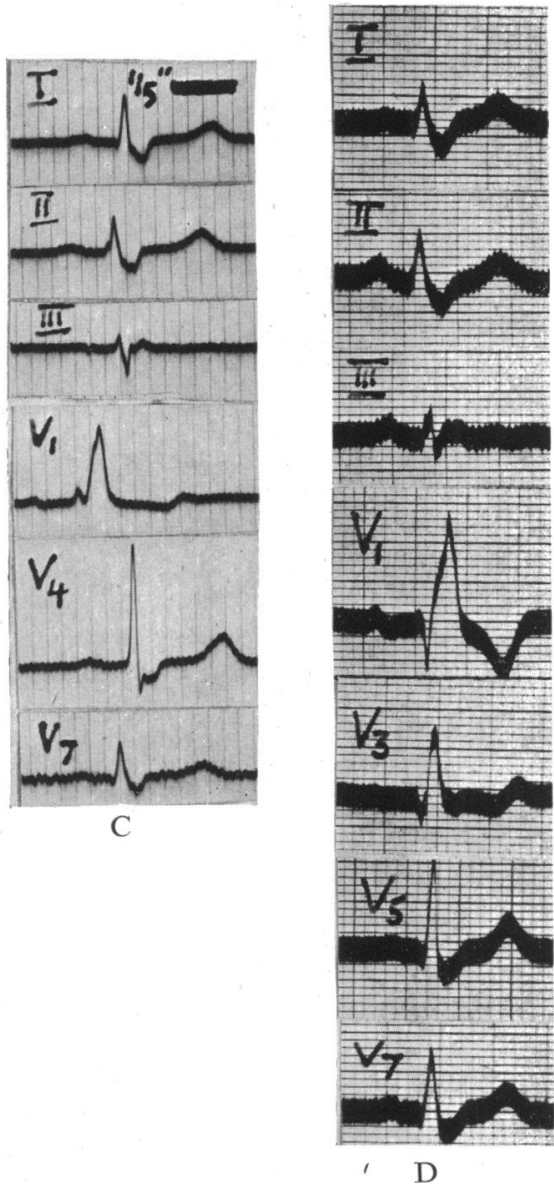

Fig. 1.-Right bundle branch block in healthy subjects. (A) Case 3. (B) Case 7. (C) Case 1. (D) Case 8.

isoelectric line up to the beginning of the $\mathrm{T}$ wave, or it started slightly below this line to merge almost immediately into the descending limb of the $\mathrm{T}$ wave; the $T$ wave was inverted in all cases except one (Fig. 1C). In left præcordial leads small $Q$ deflections were frequent; an $S$ wave was shown in all records and $\mathrm{T}$ was upright. As right branch block caused $\mathrm{T}$ inversion in right præcordial leads, so it tended to increase the voltage of $T$ in left præcordial leads.

\section{Right Bundle Branch Block with Heart Disease OTHER THAN CARDIAC INFARCTION}

This group consisted of 21 cases (see Table, Cases 21-41). In the limb leads. Q I and Q II appeared with the same frequency as in the previous group; the upstroke of $R$ and the beginning of the downstroke of $S$ had generally the same characteristics as those described for healthy subjects, but there were 2 cases in this group with a QRS complex of low voltage. In left ventricular hypertrophy from hypertension or aortic valvular disease (Fig. 2 and 3), the R-T segment often showed depression and a downward slant in lead I, or I and II; the T waves were upright in leads I and II in all cases, though occasionally of low amplitude. Left ventricular preponderance never caused $T$ inversion in right bundle branch block; $\mathrm{T}$ inversion shown in normal intraventricular conduction in lead $I$ from left ventricular preponderance was abolished with the onset of right branch block (Fig. 2, B and C), and the amplitude of $T$ waves low in normal conduction was increased in block. Chest leads were taken in 11 cases of this group, and included right præcordial leads in 7. In lead CR1 or V1, a small Q deflection was recorded once (Fig. 2A); the QRS complex showed the bifid $R$ already described, and the $T$ wave remained inverted. In records from patients 

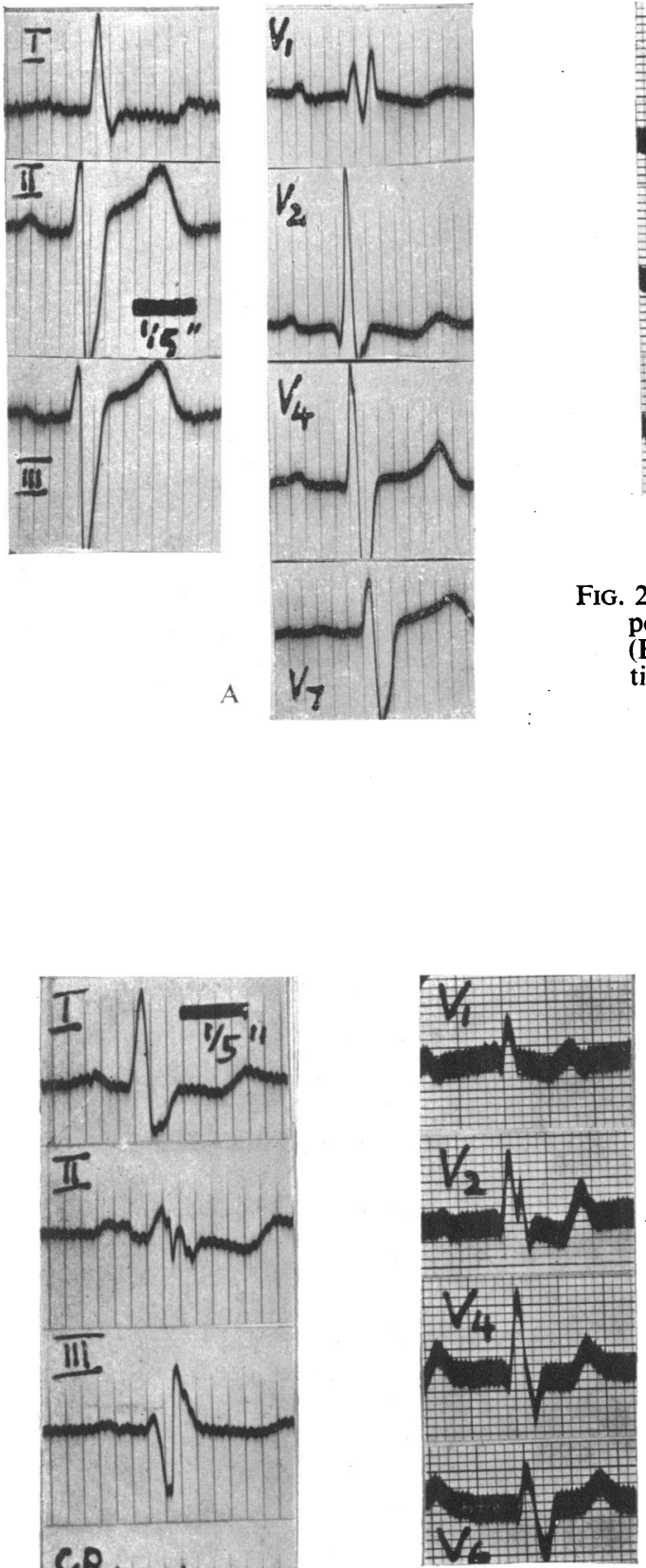

B

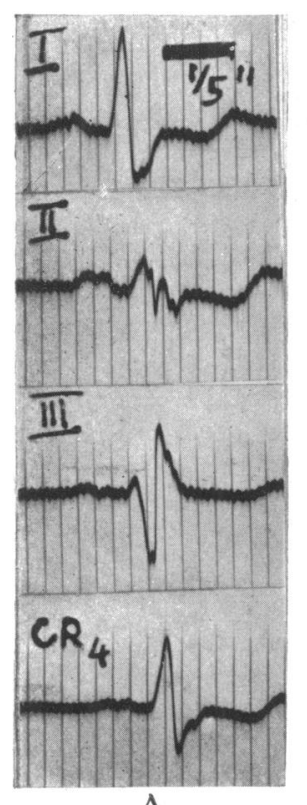

FIG. 3.-Right bundle branch block and left ventricular preponderance in patients with severe hypertension.
(A) Case 23. (B) Case 26.
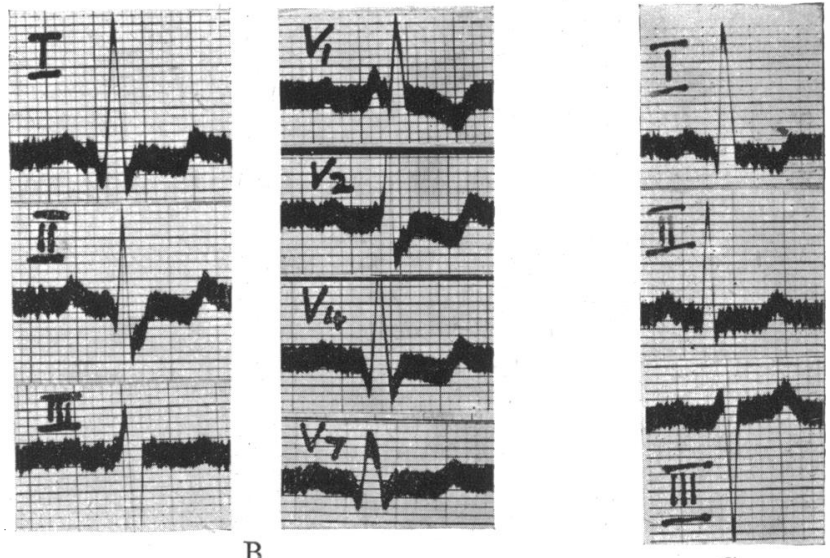

C

FIG. 2.-Right bundle branch block and left ventricular preponderance in patients with aortic stenosis. (A) Case 21. (B) Case 24. (C) Case 24 in normal intraventricular conduction.

with left ventricular hypertrophy, right præcordial leads showed the same type of slanting R-T segment as did lead $I$, and the $T$ wave was upright in some cases (Fig. 2A and 3B). In apical leads and in leads from the left lateral chest wall, $Q$ deflections were seen in 4 cases, and the deep $S$ of right branch block was present in every tracing. In records with left ventricular preponderance, the $R-T$ segment returned to the isoelectric line, or was even raised above it, as the leads were moved to the left of the chest (Fig. 2 and 3). The $T$ wave remained upright in all left præcordial positions even as far left as V7. None of the patients with left ventricular preponderance were under digitalis treatment.

\section{Right Bundle Branch Block in CardiaC INFARCTION}

Nineteen cases of anterior infarction were collected (see Table, Cases 42-60). In the limb leads, Q deflections in leads I and II were neither more frequent nor more conspicuous than in the previous two groups. A low voltage QRS complex was seen eight times; similar low voltage deflections were also recorded with heart disease other than infarction; four cardiograms showed a QRS complex of low voltage and w-shape. The $R-T$ segment in lead I was of coronary type, showing elevation and bowing, in 3 patients; in 8 other cases the R-T segment was elevated in lead I or II, but without bowing, and it was often followed by an upright T wave of normal appearance (Fig. 4, A and B); this 


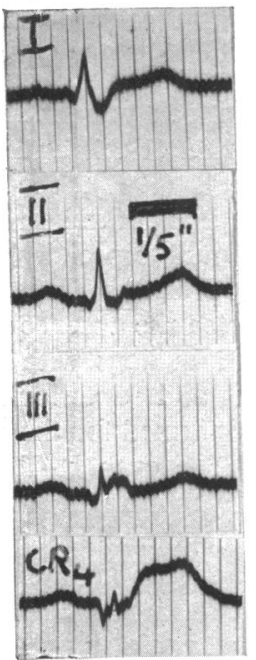

A
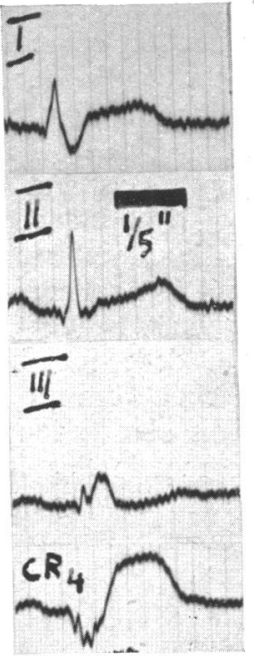

B

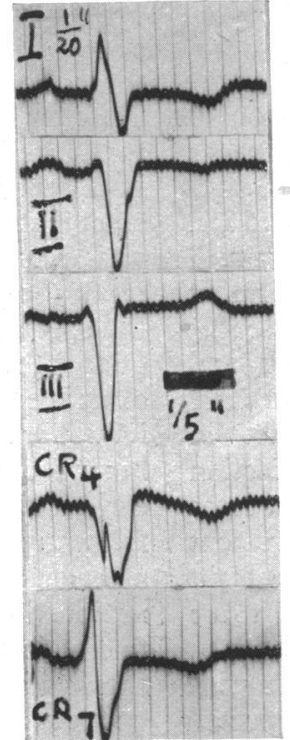

$\mathrm{C}$

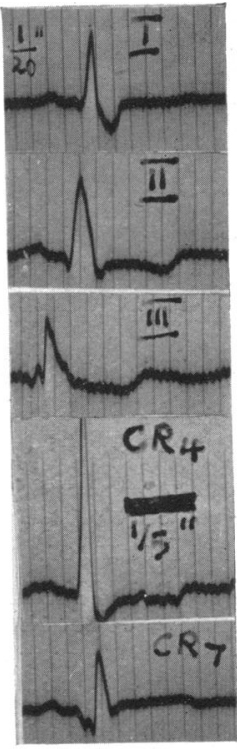

D

Fig. 4.-Right bundle branch block and anterior cardiac infarction. (A) Case 42 (on day of infarction). (B) Case 42 (7 days later). (C) Case 43. (D) Case 44. (E) Case 46.
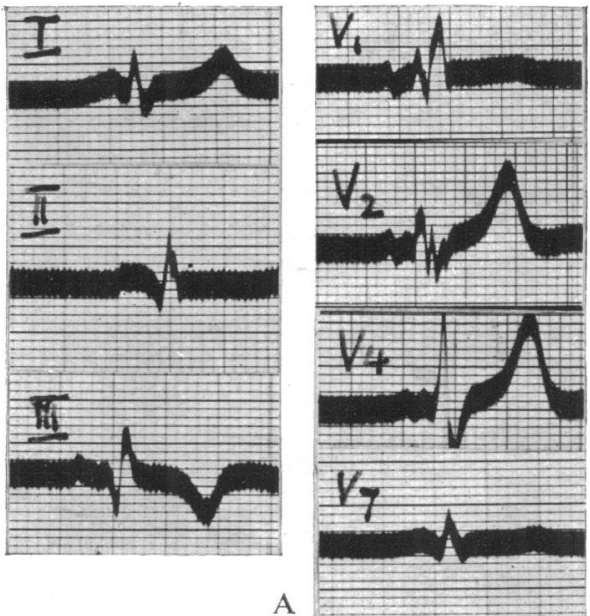

Fig. 5.-Right bundle branch block and posterior cardiac infarction. (A) Case 61. (B) Case 64. (C) Case 62.

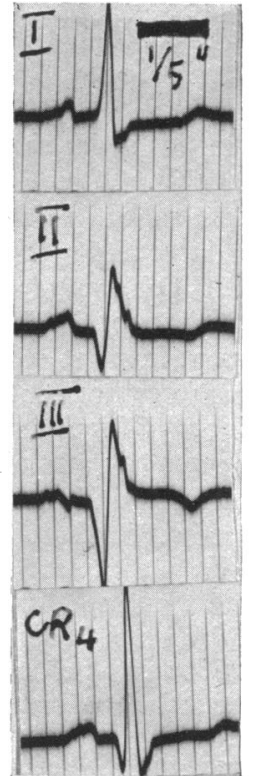

B

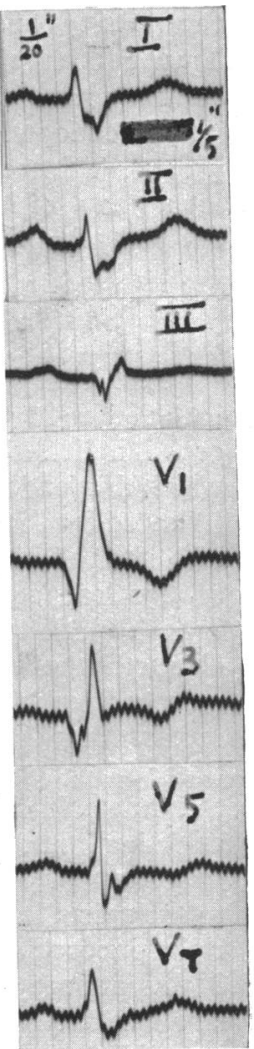

$\mathrm{E}$

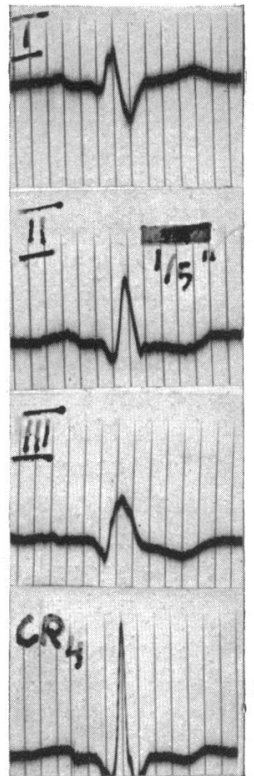

C 
form was presumably due to the tendency of the $\mathrm{T}$ wave to remain upright in right branch block, and so to prevent the development of typical " coronary" changes. In contrast to the previous two groups, $T$ inversion was a frequent finding in the later stages of infarction; it occurred in lead $I$ in 7 and in lead II in 5 out of 19 cases (Fig. 4, C and D). A number of extrasystoles were seen and examined, but they showed no modifications indicating infarction.

Chest leads were taken in 17 of the 19 cases, and included right præcordial leads in 11. Lead CR1 or V1 indicated the lesion in 9 out of 11 cases in which this lead was taken, by showing a $Q$ deflection followed by a late $R$ with a single peak; recent cases also showed coronary $\mathbf{R}-\mathrm{T}$ changes. Involvement of this lead seemed to occur more often in right branch block than in normal conduction and to be characteristic of the block; it was not due to a greater frequency of septal infarcts in records with bundle branch block as there was one patient (Case 54) whose cardiogram after infarction showed a characteristic $Q$ in lead V1, only in block and not at other times, in normal conduction. The $Q$ deflection or $\mathrm{R}-\mathrm{T}$ changes of infarction extended to the apical lead in 5 patients, but were confined to right præcordial leads in 3 (Fig. 4E); in such cases it was important to be certain of the absence of a small initial $R$ wave (compare Fig. 1D and 4E). Lead V1 remained unaffected in two records: in one the lesion was shown in the apical lead (Case 60), and in the other in a lead from the left lateral chest wall (Case 57). Six præcordial cardiograms did not include lead CR1 or V1; in five, changes of infarction appeared in the apical lead (Fig. 4, A to C), and in one in lead CR7 (Fig. 4D).

There were 12 cardiograms in this series showing posterior wall infarction (see Table, Cases 61-72). With the exception of one case of old infarction (Case 71), all tracings exhibited large and significant Q deflections in lead II (Fig. 5); Q I was no more frequent than in any previous group; Q III and inversion of T III, though present in most records, were not significant as they also occurred in right branch block without infarction. T I was upright in all cases, but T II was often abnormal. A coronary type of R-T segment in lead II or III or both was seen in 4 cases. The chest leads analysed in this group included 9 records with apical leads, and 4 with more complete cardiograms. In 3 out of 4 cases, T was upright in lead CR 1 or V1 (Fig. 5A); apical leads showed $Q$ deflections in 4 cases and $\mathrm{R}-\mathrm{T}$ depression in recent posterior infarctions.

\section{Discussion}

The preceding analysis has demonstrated a number of modifications of the electrocardiogram of cardiac infarction caused by the simultaneous presence of right bundle branch block. Soon after the common form of right branch block was first recognized in America by Wilson et al. (1934) and in England by Evans and Turnbull (1937), the combination of right branch block and infarction was examined by several authors, and especially by Wilson and his collaborators. For the limb leads, Rosenbaum et al. (1944) reported the absence of significant.$Q$ deflections in lead $I$ in dogs with experimental right branch block and anterior infarction. This observation was confirmed for the human cardiogram in this study. The even R-T elevation, without bowing and with an upright $T$ following it, described here for leads I and II in anterior infarction with right branch block, was not previously discussed, although it was a frequent finding in various published tracings; it was also well shown in cardiograms of dog experiments (Rosenbaum et al. (1944), dogs 66 and 71, and Unghváry (1942)). Inversion of T in lead I and II is, of course, a classical sign of anterior infarction, and its significance in records with right branch block had previously been reported by Master, Dack, and Jaffe (1938). The modification of the $T$ wave pattern noted in this study concerned the tendency of of $T$ to remain upright in all cases of right branch block, and especially also in cases with associated left ventricular preponderance. $T$ wave changes, therefore, occurred at a later stage of infarction than in normal conduction, and the significance of $T$ inversion, when present, was enhanced.

Wilson et al. (1944) first described the characteristic præcordial cardiogram of anterior infarction, with a $Q$ replacing the initial $R$ of right branch block in lead V1; in the present series, right branch block caused no important modifications of the signs of infarction in apical leads or in leads from the left lateral chest wall, but lead CR1 or V1 indicated the infarct more often than would be expected in normal intraventricular conduction; this seemed independent of the septal extension of the infarcted area expected in many cases of branch block.

No modifications of the limb lead or precordial cardiogram of posterior infarction have previously been reported. A number of cases here discussed showed upright $T$ waves in chest lead CR1 or V1.

It is now possible to describe, with the help of the preceding analysis, the electrocardiographic signs diagnostic of infarction in the presence of right bundle branch block. The following signs were significant in the limb leads: a w-shaped QRS complex of low voltage and a coronary $R-T$ segment with a coronary $\mathrm{T}$ wave in lead $\mathrm{I}$; an even elevation of the $\mathrm{R}-\mathrm{T}$ segment followed by a normal $\mathrm{T}$ wave 
and, later, inversion of $\mathrm{T}$ in lead I or II or both. The w-shaped QRS complex could not be accepted as conclusive because of the difficulty of distinguishing, in a given case, this form and any other low voltage QRS complex without the w-shape. Inversion of $T$ in lead II was significant except in cases showing the classical and rare form of right branch block; it was, therefore, of no value if $R$ in lead III was conspicuous and taller than $R$ in lead II, and if $R$ in lead I also was of low voltage. Using these signs, the lesion was diagnosed in the limb leads in 16 out of 19 cases of anterior infarction.

This result is not in agreement with previous observations. Wood, Jeffers, and Wolferth (1935) first reported that right branch block may mask the signs of infarction in the limb leads. Master, Dack, and Jaffe (1938) stated that in the presence of right branch block infarction could be diagnosed in two thirds of the cases, and that præcordial leads were more helpful than limb leads; Stokes (1947) quoted this opinion and agreed with it. Wilson et al. (1944) reported that in right branch block signs of infarction were rare in the limb leads, but were usually shown in præcordial tracings; this view was also expressed by Goldberger (1947) and Carlotti (1947); Rosenbaum et al. (1944) came to the same conclusion for dogs with experimental right branch block and anterior infarction. The explanation for this difference of opinion came from a consideration of the criteria of infarction in the limb leads. In the past, limb lead cardiograms have not been regarded as diagnostic of infarction if the classical signs of infarction were absent. It was here shown that the diagnosis can often be made if the signs include $\mathrm{R}-\mathrm{T}$ elevation or $\mathrm{T}$ inversion, and if the tracings are not expected to show significant $Q$ deflections.

Diagnostic signs of infarction with conspicuous $Q$ deflections and classical $R-T$ changes were seen in the præcordial cardiogram of all 19 cases here reported; in tracings with signs of infarction in apical or left lateral chest leads, the limb leads showed the lesion as well, but right præcordial leads indicated infarction in 3 records in which all other limb and chest leads were negative; in such cases it was important to be certain of the absence of a small initial $R$ wave in lead CR1 or V1.

The diagnosis of posterior infarction could be made from the presence of conspicuous $Q$ deflections in lead II and from coronary R-T changes in lead II and III in all but one case reported here; the præcordial cardiogram showed upright $T$ waves in lead CR1 or V1 in some tracings; this sign had no diagnostic significance as it was not seen in all records of posterior infarction and because it was also present in other conditions, especially in left ventricular preponderance; yet it gave valuable help in the analysis of some tracings. In Case 71 an upright $T$ wave in lead CR1 was the only abnormality in limb and chest leads of a patient known to have had posterior infarction in the past, and a flat $T$ wave in a case of anterior infarction (Case 56) suggested an associated lesion, which was shown to be an old posterior infarct by the limb leads; an upright $\mathrm{T}$ in lead V1 of another patient with anterior infarction (Case 60) was explained when left ventricular hypertrophy was found on necropsy.

For the purposes of clinical diagnosis, the limb leads furnished all essential information for the diagnosis of cardiac infarction in most cases; they also indicated left ventricular preponderance. Chest leads CR1 or V1 confirmed the presence of right branch block and disclosed a small number of infarcts not shown by any other lead. The combination of limb leads with lead CR1 or V1 revealed all lesions recorded with more numerous chest leads, and thus satisfied the clinical needs in the 31 cases of right bundle branch block and cardiac infarction reviewed here.

\section{Summary and Conclusion}

It was the object of this paper to inquire into the modifications of the electrocardiogram of cardiac infarction in the presence of right bundle branch block, and to examine the criteria necessary for the diagnosis of infarction. The investigation consisted in an analysis of cardiograms with right branch block taken from healthy subjects, from cases with heart disease other than infarction, and from patients with cardiac infarction. Twentythree patients with right branch block came under personal observation and 49 reported cases were added. Right bundle branch block is shown to cause certain modifications of the cardiographic signs of infarction. In the limb leads of anterior infarction, significant $Q$ deflections are absent in lead I; the R-T segment often assumes a characteristic shape in lead I or II, showing elevation without bowing, and is then followed by a $T$ wave of normal appearance; when $T$ inversion takes place in lead I or II, it more certainly indicates infarction than $T$ inversion in normal conduction, because this change does not occur from left ventricular preponderance in right branch block: In the præcordial cardiogram the infarct is more often shown in CR1 or V1 leads than would be expected in normal conduction; involvement of this lead appears to be independent of the septal extension of the infarct expected in cases of bundle branch block. Right branch block does not change the classical signs of posterior infarction in the limb 
leads; in chest leads, the $\mathrm{T}$ wave is upright in lead CR1 or V1 in some cases of posterior infarction.

The diagnosis of anterior infarction can be made in the limb leads in many cases if the signs include $R-T$ elevation or $T$ inversion, and if the tracings are not expected to show significant $Q$ deflections; infarction is shown by apical or left lateral chest leads when it is also shown by the limb leads, but lead CR1 or V1 occasionally registers the lesion when all other leads are negative. The diagnosis of posterior infarction is made from the presence of conspicuous $\mathrm{Q}$ deflections in lead II and of coronary $\mathbf{R}-\mathbf{T}$ changes in lead II and III. The præcordial cardiogram may show upright $T$ waves in lead CR1 or V1; although this sign has no diagnostic value, it is helpful in the interpretation of some electrocardiograms.

The limb lead cardiogram in conjunction with lead CR1 or V1 provides the necessary information for the diagnosis of cardiac infarction and right bundle branch block.

I wish to place on record my gratitude to Dr. William Evans for much encouragement and helpful criticism in the study of cardiology and in the preparation of this paper.

\section{REFERENCES}

Appelbaum, E., and Nicolson, G. H. B. (1934). Amer. Rosenbaum, F. F., Erlanger, H., Cotrim, N., Johnston, Heart J., 10, 662.

Bayley, R. H. (1934). Amer. J. med. Sci., 188, 236.

Carlotti, J. (1947). Arch. Mal. Caur, 40, 99.

F. D., and Wilson, F. N. (1944), Amer. Heart $J ., 27,783$.

Conneau, W. J., Hamilton, J. G. M., and White, P. D. (1938). Amer. Heart J., 15, 276.

Soulié, P., and Joly, F. (1948). Arch. Mal. Caur, 41, 130.

Stenström, H. (1927). Act. med. scand., 67, 351.

Stokes, W. (1947). Brit. Heart J., 9, 267.

Curtis Bain, C. W., and Redfern, E. Mc. (1948). Brit. Heart J., 10, 9.

von Deesten, H. T., and Dolganos M. (1934). Amer. J. med. Sci., 188, 231.

Evans, W., and Turnbull, H. M. (1937). Lancet, 2, 1127.

Goldberger, E. (1947). Unipolar Electrocardiography, Henry Kimpton, London.

Katz, L. N. (1941). Electrocardiography, Henry Kimpton, London.

Levine, S. A. (1929). Medicine, 8, 245.

Master, A. M., Dack, S., and Jaffe, H. L. (1938). Amer. Heart J., 16, 283.

Jaffe, H. L., Dack, S., and Grishman, A. (1944).

Unghváry, L. (1942). Zeitsch. Klin. Med., 141, 557.

Wilson, F. N., Johnston, F. D., Hill, I. G. W., Macleod, A. C., and Barker, P. S. (1934). Amer. Heart J., 9, 459 .

,$- \quad$, Rosenbaum, F. F., Erlanger, H., Kossman, C. E., Hecht, E., Cotrim, N., de Oliveira, R. M., Scarsi, R., and Barker, P. S. (1944). Ibid., 27, 19.

Wolferth, C. C., and Livezey, M. M. (1947). Ibid., $34,1$.

Wood, F. C., Jeffers, W. A., and Wolferth, C. C. (1935). Ibid., 10, 1056.

Ibid., $27,801$.

Yater, W. M. (1938). Arch. intern. Med., 62, 1. 